secondary handicap and promote social and cultural reintegration (Royal College of Psychiatrists, 2004)

HOLLOWAY, F. (2005) The Forgotten Need for Rehabilitation in Contemporary Mental Health Services. Royal College of Psychiatrists. http:// www.rcpsych.ac.uk/pdf/frankholloway_oct05.pdf

ROYAL COLLEGE OF PSYCHIATRISTS (2004) Community Mental Health Care (Council Report CR124). Royal College of Psychiatrists. http:// www.rcpsych.ac.uk/files/pdfversion/cr124.pdf

Marc Lyall Specialist Registrar, Newham Rehabilitation and RecoveryTeam, Warton House, 150 High Street, Stratford, London E15 2NE, email: marc.lyall@elcmht.nhs.uk, Dirk Claassen Consultant Psychiatrist, Newham Rehabilitation and RecoveryTeam

doi: 10.1192/pb.31.8.315b

\section{Simulated patients}

As a former professor of psychiatry and a current simulated patient I was interested in the paper of Eagles et al (Psychiatric Bulletin, May 2007, 31, 187-190). I have been doing such (voluntary) work for about 5 years, simulating psychiatric and general medical/surgical patients both for teaching sessions and in objective structured clinical examinations (OSCEs). I have also participated in OSCEs for higher exams for occupational health medicine but not yet for psychiatry. I find it a very interesting experience, and so far have not succumbed to the stress mentioned by Eagles et al. There is a bank of some 400 of us in Sheffield, a mixture of volunteers, actors, 'real ex-patients' and former clinicians of various specialties.

The usual practice is to be given a script about a week before, and once learnt one can usually trot it out realistically about 10-15 times in a day, spread over 4 or 5 sessions. I have been prepared to take on more or less any condition - the only one I drew the line at was that of a 27-yearold with schizophrenia; it wasn't the schizophrenia which troubled me, but just could not satisfy myself I could act the 27 years convincingly. It was taken on by a younger actor.

We also lend ourselves for standard physical examination - blood pressure, temperature, chest examination, etc. In these days of MRSA, I was undergoing a chest examination in a rather draughty room; the young lad came in his white coat, duly washed his hands with alcohol rub, said 'Oh my hands are cold' and proceeded to rub them on his white coat to warm them before he put them on my chest. Does he get failed for poor hygiene, or a distinction for concern for the patient's comfort?

Another heart-warming incident occurred at the end of a lecture in which I was demonstrated as a widowed hypertensive patient living alone who was worried in case he collapsed and fell down the stairs. A young student came up to me and said, 'I hope you don't mind me telling you, but my granny is like you, but she has an alarm round her neck and she can call for help if she needs to.' Another distinction.

On one occasion I was there for an abdominal examination when one of the demonstrators was called away for an emergency. I found myself taken out of bed and reverted to being a doctor, teaching for the rest of the morning.

You can appreciate I find it a rewarding, entertaining and amusing experience, perhaps repaying some of the satisfaction I achieved during my teaching and clinical career. I think it is true to say that the majority of my fellow simulators, whatever their background, feel the same way, putting something back into the system in return for whatever help they have gained in the past - it is our National Health Service.

Philip Seager email: pseager@btinternet.com doi: $10.1192 / p b .31 .8 .316$

\section{Work-related stress}

Murdoch \& Eagles (Psychiatric Bulletin, April 2007, 31, 128-131) list a number of stress factors identified by consultant psychiatrists. Conspicuous by its absence is any reference to stressful relationships with colleagues. Are we a profession in denial? Any internet search for information regarding causes of work-related stress (e.g. http://www.bbc.co.uk) will indicate that a well-recognised cause is relationships with colleagues. This was alluded to by Mackirdy (Psychiatric Bulletin, August 2006, 30, 283-285) Specifically, she cautioned that specialised teams can lead to 'boundaries which can deepen into dangerous chasms unless energy is specifically directed into border diplomacy and efficiency.

Murdoch \& Eagles quite rightly suggest that given our understanding of stress it would be 'unfortunate if we do not utilise these skills to our mutual benefit in combating work-related stress.' Of course, as anyone with a basic grasp of problemsolving knows, clearly identifying the problem is key to solving it.

Mary Davoren Senior House Officer, Mater Psychiatric Scheme, Dublin, *MacDara McCauley Consultant Psychiatrist, St. Brigid's Psychiatric Hospital, Ardee, County Louth, Ireland

doi: 10.1192/pb.31.8.316a

\section{Goldberg and Huxley's model 27 years on}

Over 25 years ago Goldberg \& Huxley (1980) proposed a widely recognised pathway to psychiatric care. This model, which has since been refined (Goldberg, 1995), predicts that 20.8 adults per 1000 population per year will be in contact with specialist mental health services. We have previously demonstrated that this model underestimated the utilisation of specialist psychiatric services in North East Edinburgh in 2003 (O'Sullivan et al, 2005) We decided to resurvey referrals in the same area for 2005 to attempt to replicate our findings.

We recorded all new referrals from general practitioners (GPs) to mental health services among those aged 18-64 years in our sector. This included general and specialist psychiatric services, namely clinical psychology, psychotherapy, addic tions and eating disorder services. Given the emphasis on social factors in the original model, we checked for a correlation between the levels of deprivation as measured locally by the Scottish Index of Multiple Deprivation (SIMD; http:// www.scotland.gov.uk/Topics/Statistics/ SIMD/Overview) and referral rates from individual GP practices

There were 1541 new individual referrals of those aged 18-64 years, which is equivalent to 24.6 per 1000 catchment population per year (95\% Cl 24-26). New referrals alone exceeded the number predicted in the model. Spearman's rank correlation coefficient between the SIMD score of individual practices and referral rate was 0.44 .

In an atmosphere of continual change in the National Health Service, we urge service planners to be mindful of the gross underestimation of current referral to psychiatric services by Goldberg and Huxley's model.

GOLDBERG, D. (1995) Epidemiology of mental disorders in primary care settings. Epidemiologic Reviews, 17, 182-190.

GOLDBERG, D. \& HUXLEY, P. (1980) Mental IIIness in the Community: The Pathway to Psychiatric Care. Tavistock Publications.

O'SULLIVAN, T., COTTON, A. \& SCOTT, A. (2005) Goldberg and Huxley's model revisited. Psychiatric Bulletin, 29, 116 .

Treasa O'Sullivan Specialist Registrar, Ravneet Batra Specialist Registrar, Margot Nolan Specialist Registrar, *Allan Scott Consultant Psychiatrist, Andrew Duncan Clinic, Royal Edinburgh Hospital, MorningsideTerrace, Edinburgh EH10 5AF

doi: $10.1192 / p b .31 .8 .316 b$

\section{Policing psychiatric units}

As clinicians studying outcomes of violence by patients admitted to hospitals, the benefits of the scheme described by Mann et al (Psychiatric Bulletin, March 2007, 31, 97-98) appear initially impressive. We are aware of the benefits 